\title{
Design Multiband Compact Microstrip Circular Slot Fractal Meta-Surface Antenna
}

\author{
Noor Fadhel Habib ${ }^{1 *}$, Ahmed Ghanim Wadday ${ }^{1 *}$ and Faris Mohammed Ali $^{1}$ \\ ${ }^{1}$ Communications Tech. Eng. Dept., Al-Najaf Technical Engineering College, Al-Furat Al-Al-Awsat Technical University ATU, \\ Al-Najaf, Republic of Iraq \\ *Corresponding author E-mails: noorfathel20@gmail.com \& ahmadghw@atu.edu.iq
}

\begin{abstract}
Multiband antenna with compact size is important today in design antenna. Widening the bandwidth and get multi-band frequencies is one goals when using fractal geometry. In this paper, design multiband compact microstrip circular slot fractal metasurface antenna for $\mathrm{C} \& S$ bands application which has covered 1 to $7 \mathrm{GHz}$ is proposed. The adopted antenna is designed on dielectric substrate from FR4 material. The gain of this antenna is $6 \mathrm{~dB}$ and its efficiency is approximately $(90 \%)$. Modelling and performance are evaluated by using the commercially available EM (Electromagnetic) Simulator, the Commercial Microwave Studio Suite (CST ).
\end{abstract}

Keywords - Microstrip, Fractal, Metasurface, Circular slot antenna

\section{INTRODUCTION}

One of the most important standards in microwave components and modern communication systems is small size and high performance. The microstrip antenna is a good choice to have a low-profile structure, but it suffers from low gain and efficiency and narrow bandwidth. To circumvent these problems, integrating another part assisting to improve the antenna gain, efficiency, and bandwidth will be useful [1]. The miniaturization of microstrip components remains a challenge so different techniques have been developed during past years such fractal geometry [2] and metasurface techniques [3].

The demand for compact antennas is increasing in wireless applications such as mobile phones and laptop and other wireless applications so, the use of the metasurface with fractal techniques can be considered one of the best ways to achieve high performance in a small size, through which the gain, bandwidth, matching and efficiency are improved [4].

Metasurface which are 2D surfaces, consisting of electrically small resonators, will keep the overall antenna volume is low profile. The characteristic of metasurface having both negative $\epsilon$ and $\mu$, is not available in nature, so this material can only be realized if it is engineered. This material is known as Left-
Handed Material (LHM) or Double Negative Material (DNG) made improved the performance of antenna especially gain [5-7].

Using a fractal geometry in design makes the proposed antenna resonating at multiple frequencies, thereby increasing the bandwidth [8] .In [9] implemented the properties of metasurface as negative $\epsilon$ and $\mu$ by designing Minkowski fractal with Closed Split Ring Resonators (CSRRs).

In [10] suggested antenna based on periodic metamaterial and designed double-fractal layers and they get broadband left-handed metamaterial.M. R. I. Faruque \& M. M. Hasan proposed design "Tree-shaped fractal meta-surface with left-handed characteristics" and they get tri-band resonances frequencies [11]. In [12] Shashi Bhushan \& Pramod Kumar suggested design Sierpinski's carpet fractal shape with periodic structures to enhance the bandwidth of the antenna and get multiband.

In this article, proposed the combination between the metasurface and fractal technique to design multiband circular fractal metasurface antenna to achieve high performance with compact size. Different cases such as the effect of the varying the width of the feeding line and the radius of the middle circle on the overall performance of the antenna were analysed. The 
Al-Furat Journal of Innovation in Electronics and Computer Engineering (FJIECE) is an international, open access, interdisciplinary, quarterly, and double blind peer-reviewed journal published by Al-Furat Al-Awsat Technical University/Iraq. It is dedicated to the latest advancement in Electronic Engineering, Computer engineering, and their related and subfields.

construction of this paper as follows. In section two, the structure of the proposed design is offered. In this section, the pprocedure for the antenna design is explained. In section three the simulation results are discussed. Section four contains the conclusions for this article.

\section{THE PROPOSED ANTENNA STRUCTURE}

Based upon feed coupling with the ground plan, a microstrip slot antenna was created. In recent decades [13-14] the diverse forms of the antenna have been studied, such as rectangular and circular shape. The lower resonant frequency $f l$ in terms of the main circle diameter $(a)$ is given by:

$$
f 1=\frac{v}{2 a \sqrt{\epsilon}}
$$

$v$ : the speed of light

The proposed design antenna consists from the circular fractal slot on the ground plan (when slots are loads over the ground plan this called defected ground structure) and then add four rectangular slots at the edges of the circle, each slot rotated by an angle $45^{\circ}$. The design of fractal antenna begin from circular with a radius is $a=4 \mathrm{~mm}$ after that add two small circular slots at the radius $b=2 \mathrm{~mm}$ removed from the first circle and finally design 4 circulars at $c=1 \mathrm{~mm}$ two inside one circular slot and can repeat these steps for more iterations. At the centre of the main circular slot put disk at radius $d=5.8 \mathrm{~mm}$ for matching, and the feeding line is connected to $50 \Omega$. Proposed antenna designed on FR4 substrate $40 * 40 \mathrm{~mm}^{2}$ with thickness $1.6 \mathrm{~mm} \epsilon=4.3$ and the ground plan from copper material with a thickness of $0.035 \mathrm{~mm}$. The feeding line length is e $=20 \mathrm{~mm} \&$ the width is $\mathrm{i}=1.6 \mathrm{~mm}$.

\section{TABLE I: DIMENSION OF THE PROPOSED ANTENNA}

$\begin{array}{lll}\begin{array}{l}\text { Parameter } \\ \text { the width \&length of } \\ \text { substrate } \\ \text { the width \& length } \\ \text { of ground }\end{array} & \begin{array}{l}\text { Dimension }(\mathrm{mm}) \\ \begin{array}{l}\text { The radius of } \\ \text { circular slot 1 }\end{array}\end{array} & \begin{array}{l}\text { Symbols } \\ \text { W1=L1 }\end{array} \\ \begin{array}{l}\text { iteration } \\ \text { The radius of } \\ \text { circular slot 2 }\end{array} & 40 \mathrm{~W} 2 \\ \begin{array}{l}\text { iteration } \\ \text { The radius of } \\ \text { circular of 3 }\end{array} & 2 & \mathrm{a} \\ \begin{array}{l}\text { iteration } \\ \text { The radius of center } \\ \text { desk }\end{array} & 1 & \mathrm{~b} \\ \begin{array}{l}\text { The length of } \\ \text { feeding line }\end{array} & 5.8 & \mathrm{c} \\ \begin{array}{l}\text { The width of } \\ \text { feeding line }\end{array} & 20 & \mathrm{~d} \\ \end{array}$

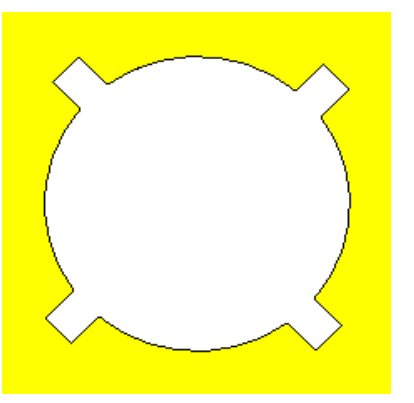

a



$\mathrm{C}$





b

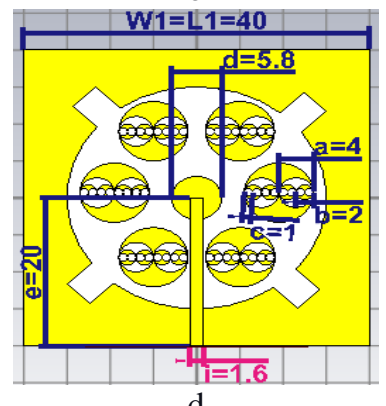

Fig.1: The layout of the modeled circular fractal meta-surface antenna (a) Circle with 4 rectangular slots only (b) First iteration (c) Second iteration (d) Third iteration

\section{RESULTS}

To analyse the behaviour of the proposed antenna the CST microwave studio package was used to simulate this antenna. The simulated results studied four states of the fractal antenna with the metasurface see Fig.1, where we followed the effect of increasing the order of iteration on the overall performance of the antenna. The results showed that the antenna has three resonance frequencies, at first step (see Figure 1(a)) which are (3.03, 4.11 and 6) $\mathrm{GHz}$ and the bandwidths are (399, 211 and 729) MHz respectively.

As for performing the second step independently, that is, at the first iteration of the circular fractal antenna (see Figure1(b)), three resonant frequencies are observed, as follows (2.8, 3.9 and 5.6) $\mathrm{GHz}$ and the bandwidths obtained at these frequencies are $(710,442$ and 390) $\mathrm{MHz}$ respectively.

On the second iteration shown in Figure1(c), three frequencies were obtained as well, and they are distributed as follows $(2.7,3.8$ and 5.5) $\mathrm{GHz}$ which have bandwidths are (715, 432 and 329) $\mathrm{MHz}$ respectively.

Finally, the third iteration shown in the Figure 1(d), where it was observed that the three resonance frequencies are distributed as follows (2.6, 3.7 and 5.4) $\mathrm{GHz}$ and have bandwidths are (785, 230 and 522) $\mathrm{MHz}$.

Through the above-mentioned practical results as seen in Figure2, notice that when increasing the number of iterations greater the wavelength, and therefore the resonance frequency will decrease with the increasing the number of iterations, according to the following relation: 
Al-Furat Journal of Innovation in Electronics and Computer Engineering (FJIECE) is an international, open access, interdisciplinary, quarterly, and double blind peer-reviewed journal published by Al-Furat Al-Awsat Technical University/Iraq. It is dedicated to the latest advancement in Electronic Engineering, Computer engineering, and their related and subfields.

$$
\lambda=\frac{v}{f}
$$

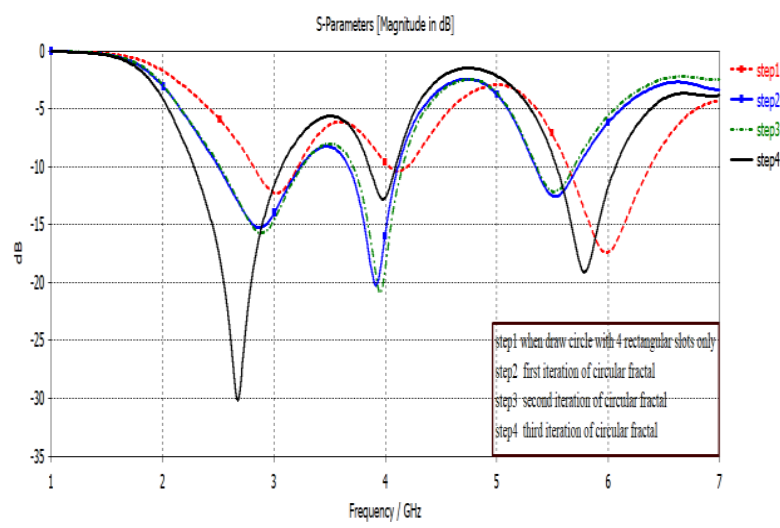

Fig. 1: The comparison between the return loss of four cases to the proposed antenna

Parameter study implemented to study the effect of changing the diameter of the intermediate circle $(d$ parameter) on the performance of the antenna where its diameter has been changed and studying the effect of five values starting from 5.8 to $7.8 \mathrm{~mm}$ and the rate of increasing is one number between each case and the other, noticed that when increasing the diameter of the circle, the antenna matching improved with a very small increase in the bandwidth.

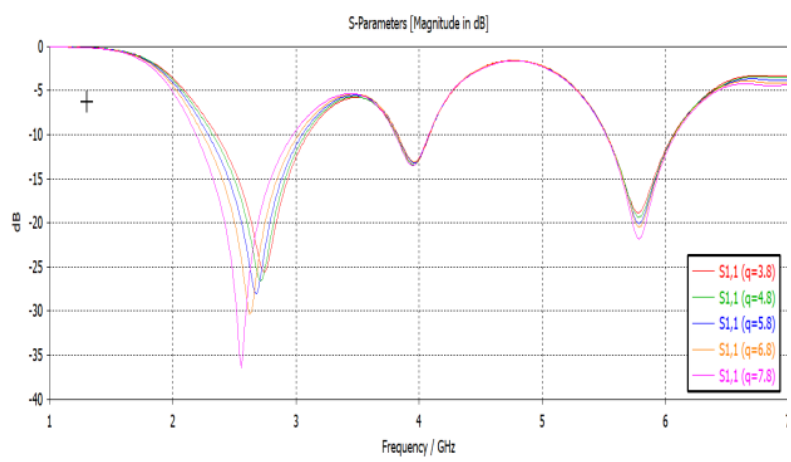

Fig. 3: The parameter study of the diameter of the middle circle on the antenna

Parameter study also investigated to study the effect of the width of the feeding line on the performance of the antenna. In this study take various values from 1.6 to $5 \mathrm{~mm}$ and observed the first and third band shifted down when increasing the width and improve the matching in these bands.

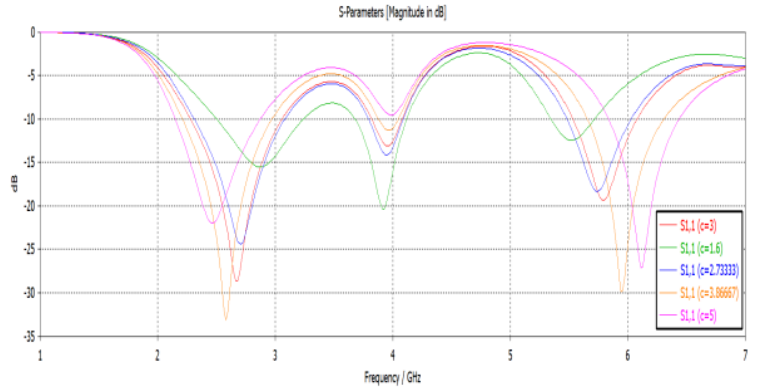

Fig.4: The parameter study of the width of the feed line on the antenna

The Figure $5(\mathrm{a}, \mathrm{b} \& \mathrm{c})$ shows the 3Dimention results of the gain at three resonance frequencies $(2.6,3.7$ and 5.4) GHz are $(4,5$ and 6$) \mathrm{dB}$.
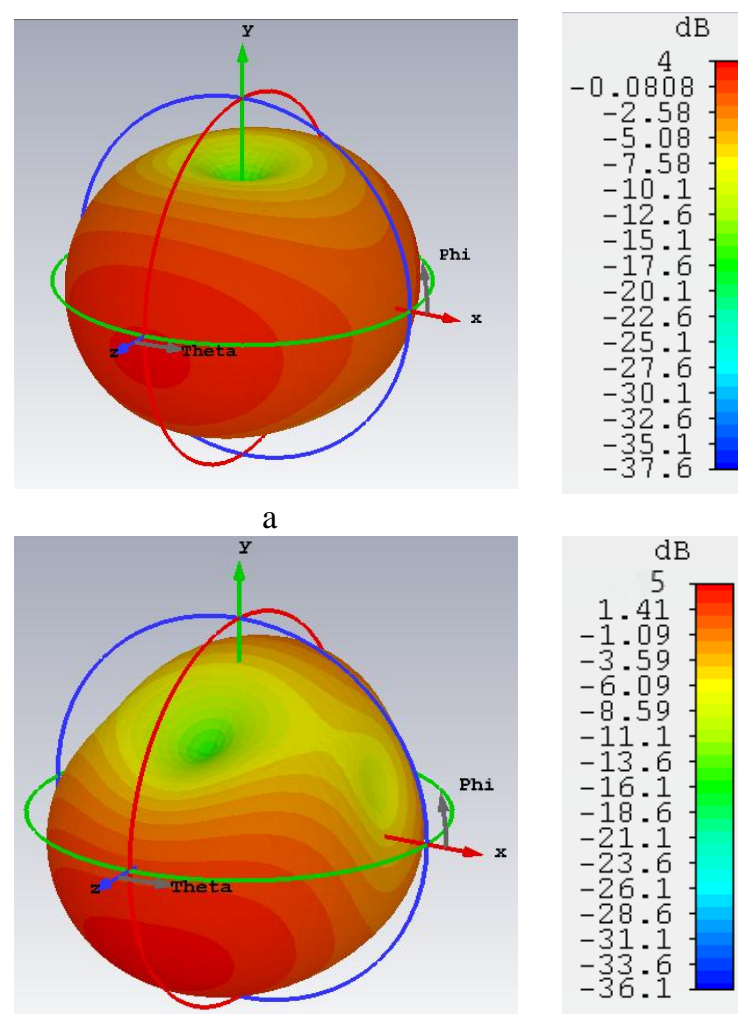

b
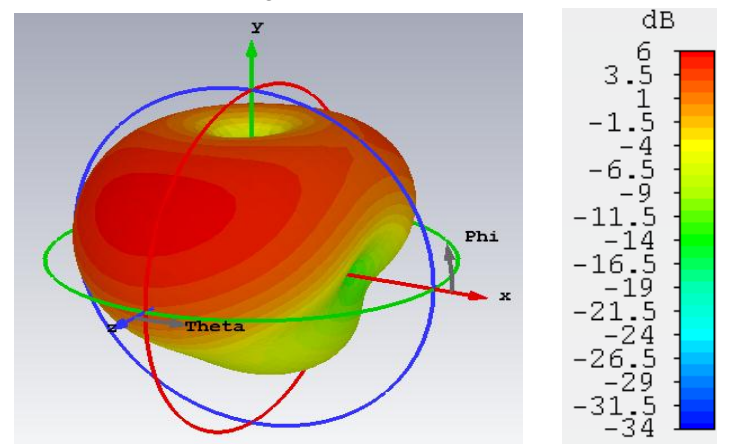

Fig.5: Simulated 3 dimensions gain at three frequencies (a) 2.6 $\mathrm{GHz}$, (b) $3.7 \mathrm{GHz}$ and (c) $5.4 \mathrm{GHz}$ 


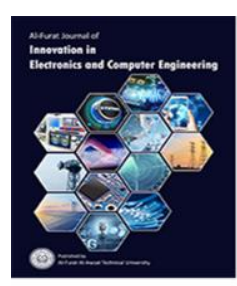

Al-Furat Journal of Innovation in Electronics and Computer Engineering (FJIECE) is an international, open access, interdisciplinary, quarterly, and double blind peer-reviewed journal published by Al-Furat Al-Awsat Technical University/Iraq. It is dedicated to the latest advancement in Electronic Engineering, Computer engineering, and their related and subfields.

Figure (6) presents the 3Dimentional directivity of the circular fractal slot antenna at three resonance frequencies (2.6, 3.7 and 5.4) GHz.

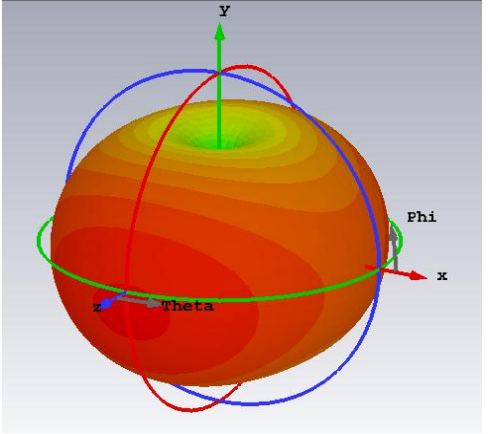

a

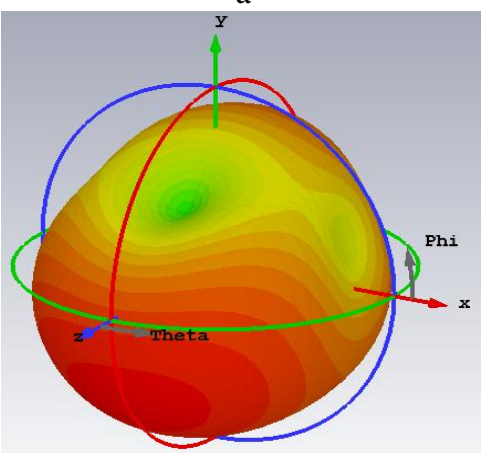

b



c
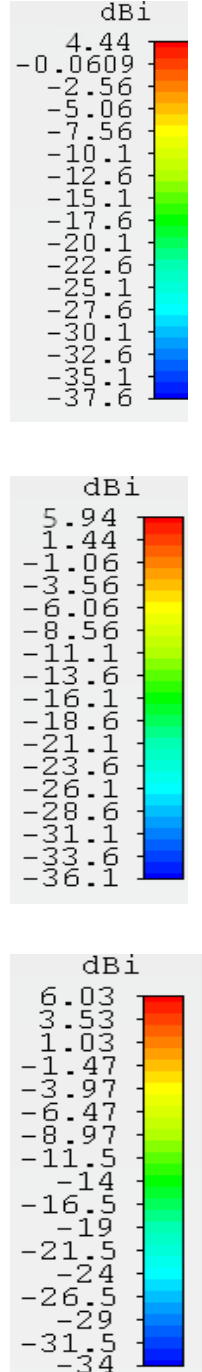

Fig.6:Simulated 3dimensions directivity at three frequencies (a) 2.6 $\mathrm{GHz}$, (b) $3 \mathrm{GHz}$. and (c) $5.4 \mathrm{GHz}$

The surface current distribution of the triple bands is seen at Figure $7(a, b \& c)$ of the proposed antenna at $(2.6,3.7$ and 5.4) $\mathrm{GHz}$ when seeing the antenna from the top view. The red-colored indicates to the area where the current is distributed, at the $2.6 \mathrm{GHz}$ the current is spreading in a small area, while at $3.7 \mathrm{GHz}$ notice the increase in the region in which the current is distributed. finally, at the 5.4 $\mathrm{GHz}$, The current distribution expanded to include the whole circle.

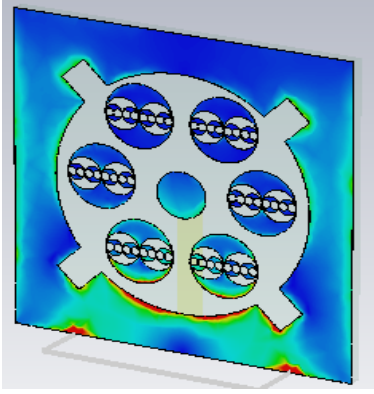

a

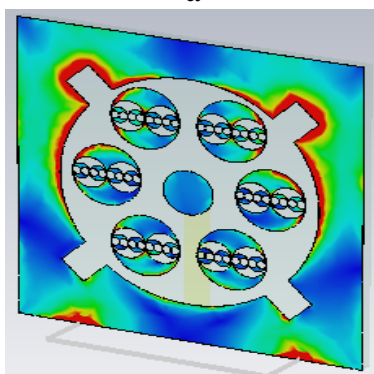

b

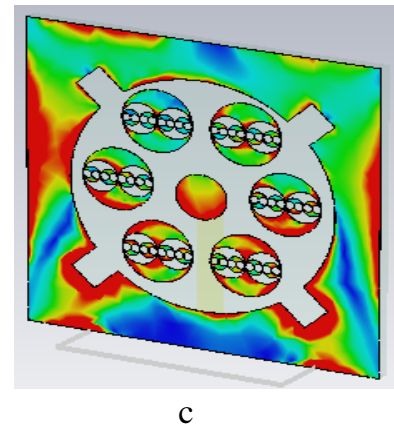

Fig 7: The current distribution of the proposed antenna at the resonance frequencies (a) $2.6 \mathrm{GHz}$, (b) $3.7 \mathrm{GHz}$ and (c) $5.4 \mathrm{GHz}$

The far-field radiation pattern properties of proposed circular fractal slot antenna with metasurface, for the length of the feed line is $20 \mathrm{~mm}$ have been calculated as seen in Fig. 8. In this state, the antenna proposed resonates at 2.6, 3.7 and $5.4 \mathrm{GHz}$ in the broadside orientation at $\varphi=0^{\circ}$ \& $\varphi=90^{\circ}$. The results obtained show the radiation patterns of the antenna at $2.6 \mathrm{GHz}$ when $\varphi=90^{\circ}$ have bi-directional radiation and Omnidirectional pattern when $\varphi=0^{\circ}$ while the radiation pattern at other frequencies are slightly different. 
Al-Furat Journal of Innovation in Electronics and Computer Engineering (FJIECE) is an international, open access, interdisciplinary, quarterly, and double blind peer-reviewed journal published by Al-Furat Al-Awsa Technical University/Iraq. It is dedicated to the latest advancement in Electronic Engineering, Computer engineering, and their related and subfields.
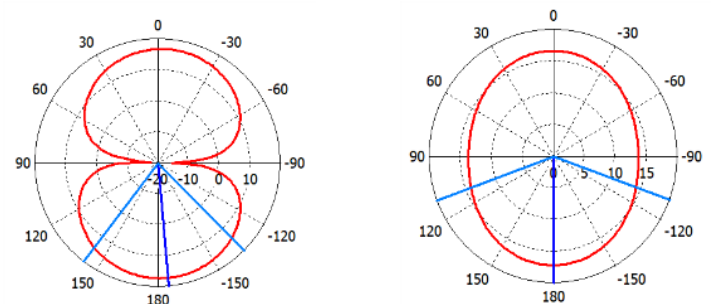

E-Plan



H-Plan

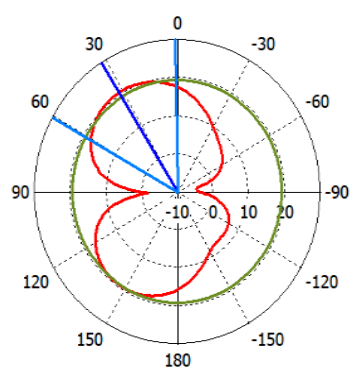

H-Plan

$\mathrm{c}$

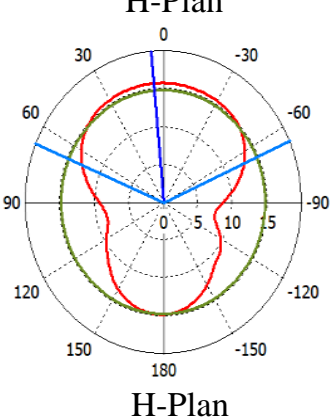

$\mathrm{b}$

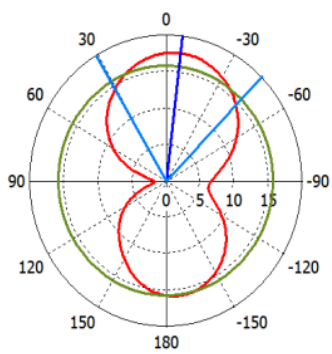

H-Plan

\section{CONCLUSION}

In this paper multiband circular fractal slot antenna with metasurface was designed for $\mathrm{C}$ and S-bands applications. the combination of the planar metasurface architecture and the fractal shapes leads to be a good way for improving microstrip patch antenna characteristics providing high performance with reduced size. The suggested antenna realized the frequency range of $1 \mathrm{GHz}$ to $7 \mathrm{GHz}$, achieving a bandwidth are $(785,230$ and 522) $\mathrm{MHz}$ at the frequencies $(2.6,3.7$ and 5.4$) \mathrm{GHz}$ respectively and the gain is $(4,5 \& 6) \mathrm{dB}$ the antenna achieving good matching at $30 \mathrm{~dB}$. Current distributions of antennas are also analysed to figure out which parts in antenna that can contribute largely to radiation in space.

\section{REFERENCES}

[1] Kuhestani, Hamed, et al. "Design of compact patch antenna based on metamaterial for WiMAX applications with circular polarization." Microwave and Optical Technology Letters 57.2 (2015): 357-360

[2] Yousefi, L., and O. M. Ramahi. "Miniaturised antennas using artificial magnetic materials with fractal Hilbert inclusions." Electronics letters 46.12 (2010): 816-817.

[3] Zarrabi, Ferdows B., et al. "Miniaturization of microstrip antenna by CRLH-TL technique." Wireless Personal Communications 81.3 (2015): 1091-1100.

[4] Varamini, Gohar, et al. "Microstrip Sierpinski fractal carpet for slot antenna with metamaterial loads for dual-band wireless application." AEU-International Journal of Electronics and Communications 84 (2018): 93-99.

Fig 8: 2 Dimension radiation pattern of the proposed antenna (a) Eplan and $\mathrm{H}$-plan at 2.6GHz (b) E-plan and H-plan at $3.7 \mathrm{GHz}$ (c) Eplan and $\mathrm{H}$-plan at $5.4 \mathrm{GHz}$

[5] Veselago, Victor Georgievich. "The Electrodynamics of Substances with Simultaneously Negative Values of Img Align= Absmiddle Alt $=\epsilon$ Eps/Img and $\mu$." Physics-Uspekhi 10.4 (1968): 509-514.

In [16] designed wide band split ring resonator for wireless application with the gain is 2-3.5 dB, while in [4] design micro-strip sierpinski fractal shape with metamaterial for dualband applications having gain is $4.5 \mathrm{~dB}$. In [17] designed circular fractal metasurface with high bandwidth have the gain around $3.6 \mathrm{~dB}$. In this paper the proposed design multiband circular fractal slot antenna with metasurface achieving gain $6 \mathrm{~dB}$ for $\mathrm{C} \& \mathrm{~S}$ bands applications. The table below show the comparison between these results.

\section{TABLE. 2 COMPARISON BETWEEN THIS RESULTS OF THE PROPOSED ANTENNA AND SOME OTHER ANTENNAS.}

$\begin{array}{lll}\text { This work 2020 } & \text { Gain } & \text { Bandwidth } \\ \text { This work 2020 } & 6 \mathrm{~dB} & \text { Triple bands } \\ \text { Ref[16] 2016 } & 3.5 \mathrm{~dB} & \text { Wide band } \\ \text { Ref [4] 2018 } & 4.5 \mathrm{~dB} & \text { Dual band } \\ \text { Ref.[17] 2019 } & 3.6 \mathrm{~dB} & \text { Wide band }\end{array}$

[6] Pendry, John B., et al. "Low frequency plasmons in thin-wire structures." Journal of Physics: Condensed Matter 10.22 (1998): 4785 .

[7] Park, Ikmo. "Application of metasurfaces in the design of performance-enhanced low-profile antennas." EPJ Applied Metamaterials 5 (2018): 11

[8] Khanna, Ghriti, and Narinder Sharma. "Fractal antenna geometries: A review." International Journal of Computer Applications 153.7 (2016).

[9] Hongnara, Tanan, Sarawuth Chaimool, and Prayoo Akkaraekthalin. "Metasurface characteristic of fractal fishnet structure and closed ring resonator." The 20th Asia-Pacific Conference on Communication (APCC2014). IEEE, 2014

[10] Kubacki, Roman, et al. "A broadband left-handed metamaterial microstrip antenna with double-fractal layers." International Journal of Antennas and Propagation 2017.

[11] Faruque, Mohammad Rashed Iqbal, M. M. Hasan, and Mohammad Tariqul Islam. "Tree-shaped fractal meta-surface with left-handed characteristics for absorption application." Applied Physics A 124.2 (2018): 127.

[12] Kumar, Shashi Bhushan, and Pramod Kumar Singhal. "Fractal Geometry with Enhanced Bandwidth Using Periodically Capacitive Loading Structure." Applications of Computing, Automation and Wireless Systems in Electrical Engineering. Springer, Singapore, 2019. 373-381

[13] Zarrabi, Ferdows B., et al. "Microstrip slot antenna applications with SRR for WiMAX/WLAN with linear and circular polarization." Microwave and optical technology letters 57.6 (2015): 1332-1338. 


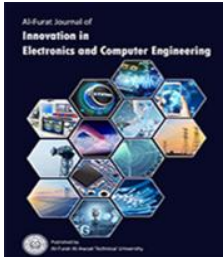

Al-Furat Journal of Innovation in Electronics and Computer Engineering (FJIECE) is an international, open access, interdisciplinary, quarterly, and double blind peer-reviewed journal published by Al-Furat Al-Awsat Technical University/Iraq. It is dedicated to the latest advancement in Electronic Engineering, Computer engineering, and their related and subfields.

[14] Wang, Xiao- Yi, and Guo- Min Yang. "Dual frequency and dual circular polarization slot antenna for BeiDou navigation satellite system applications." Microwave and Optical Technology Letters 56.10 (2014): 2222-2225

[15] Ali, Jawad K., and Seevan F. Abdulkareem. "A circle-based fractal slot antenna for dual-band wireless applications." 13th IEEE Mediterranean Microwave Symposium, MMS. Vol. 13. 2013.

[16] Rahimi, Maryam, et al. "Wide band SRR-inspired slot antenna with circular polarization for wireless application." AEU-International Journal of Electronics and Communications 70.9 (2016): 11991204

[17] Rad, Mahsa Ahmadi, Mohammad Reza Soheilifar, and Ferdows B. Zarrabi. "Compact microstrip antenna based on fractal metasurface with low radar cross section and wide bandwidth." AEUInternational Journal of Electronics and Communications 98 (2019): 74-79. 